Revista de Derecho

Universidad Católica del Norte

Sección: Estudios

Año 17 - No 2, 2010

pp. $99-132$

\title{
LA IMPRUDENCIA MÉDICA. ALGUNOS PROBLEMAS DE IMPUTACIÓN DE LO INJUSTO PENAL
}

\section{Tatiana Vargas Pinto*}

RESUMEN: Son frecuentes las consecuencias negativas para la vida y salud de las personas producto de actos médicos y, sin embargo, quienes actúan raramente deben responder civil y penalmente por los riesgos que tales actos suponen y su fin curativo. Esta finalidad explica que las conductas dolosas sean excepcionales. De allí que la responsabilidad penal en este ámbito se centre en el examen de la imprudencia. ¿Cuándo existe una imprudencia médica?; ¡cuándo procede cargar al facultativo médico con las consecuencias dańosas por su conducta? Estas son las principales preguntas que debe resolver el juzgador y que se enfrentan a diversas dificultades como: la precisión del deber de cuidado, el rol del consentimiento del paciente, la influencia del principio de confianza cuando se trabaja en equipo, etc. Semejantes problemas se abordan en general, pero también desde la práctica.

PALABRAS CLAVE: Imprudencia - actividad médica - lex artis injusto - imputación.

\section{SOME PROBLEMS OF ACCUSATION OF THE CRIMINAL UNFAIRNESS SPEAKING OF MEDICAL NEGLIGENCE}

ABSTRACT: The negative consequences to people's life and health due to medical acts are frequent, and yet, the perpetrators are seldom liable or criminally accountable for the risks that such acts suppose and their curative purpose. This final aim explains why those negligent conducts are exceptional. Therefore, the criminal accountability in this sphere focuses in the exam of negligence. When can we talk about medical negligence? When can we charge a physician for the damaging consequences of his/her conduct? These are the main questions judges

Doctora en Derecho por la Universidad de los Andes (Chile), profesora de Derecho Penal de la Universidad de los Andes (CHILE). Correo electrónico: tatianavp@uandes.cl

Fecha de recepción: 3 de octubre de 2010.

Fecha de aceptación: 20 de diciembre de 2010. 
must solve and they face diverse difficulties such as: The precision of the duty of health care, the role of consent by the patient, the influence of the principle of reliability when team working, etc. These types of problems are managed in general, but also from the practical field.

KEY WORDS: Negligence - medical activity - lex artis - unfairness accusation.

\section{1) ANTECEDENTES DE LA RESPONSABILIDAD PENAL MÉDICA DESDE UN CASO PARADIGMÁTICO}

La actual intolerancia social frente a cualquier daño se ha extendido también al ámbito médico. No estamos dispuestos a soportar consecuencias lesivas, pues "alguien" debe pagar. Resulta difícil establecer responsabilidad si ese alguien es un médico; primero, porque no suele buscar con su conducta la producción de tales resultados. Normalmente, las conductas no son dolosas. Casos excepcionales se pueden encontrar en la comisión de abortos y ciertas operaciones de cirugía estética ${ }^{1}$. Los comportamientos que pueden generar responsabilidad son en general imprudentes. Por otra parte, los riesgos propios de la actividad médica impiden aceptar fácilmente la responsabilidad por los perjuicios que provoquen. En este sentido, resulta particularmente interesante la sentencia de la Corte Suprema de 16 abril de $2009^{2}$ que, si bien casa en la forma de oficio la sentencia de alzada, sorprende al confirmar la doctrina del Segundo Juzgado del Crimen de Coyhaique y de la Corte de Apelaciones de esa ciudad, aunque esta última la sostiene únicamente respecto de la matrona y no del médico tratante. En las sentencias se condena por cuasidelito de aborto, al estimarlo un delito contra las personas, más allá del título del Código Penal que lo contempla específicamente. La sorpresa se genera no solo por admitir el cuasidelito de aborto, sino también por la argumentación de la Corte Suprema. Mantiene la condena para ambos profesionales y recurre a la protección de la madre, pero no cambia a la criatura no nacida como sujeto pasivo del delito ni a su vida dependiente como objeto de tutela afectado.

\footnotetext{
1 Ver, Corte de Apelaciones de Temuco. 5 de diciembre de 2006. Rol: 1258-2006; Corte de Apelaciones de Rancagua. 9 de marzo de 2005. Rol: 37-2005; Tribunal Oral Penal de Santiago (2º. 28 de noviembre de 2006, RUC 0500508827-7, con relación a la Corte de Apelaciones de Santiago. 26 de enero de 2007, Rol: 2556-2006; Corte De Apelaciones de Santiago. 25 de septiembre de 2007, Rol: 302-2005; Corte de Apelaciones de Santiago. 13 de mayo de 2008, Rol: 6974-2005; Corte Suprema. 18 de noviembre de 2008, Rol: 6222-2007.

2 Corte Suprema. 16 de abril de 2009, Rol: 1882-2008.
} 
La sentencia de la Corte Suprema en su considerando vigésimo primero expresa que: "...en ningún caso implica que aquellas conductas culposas que atentan en contra de la madre, quien se erige como un sujeto pasivo de la acción desplegada, aun cuando solo puedan afectar la vida e integridad física o psíquica de ella, no puedan ser comprendidas en las figuras previstas en los artículo 490 y 491 del Código Penal, en tanto afectan la salud integral de la primera, también tutelada por dichas figuras.

En el caso en análisis no cabe duda que las conductas, o más bien las omisiones en que incurrieron los profesionales de la salud, y especialmente el médico Redondo Caro en la atención inicial del proceso de parto, se materializaron en la madre, afectando también la vida de la hija que llevaba en su vientre, y que dependía de ella, de manera que sujeto pasivo podría ser la madre, en este caso la paciente, que no recibió la atención médica necesaria y oportuna que debía ser dispensada por el equipo médico particular tratante, quienes generaron con su comportamiento un riesgo jurídicamente desaprobado por el ordenamiento...".

Sin, embargo, agrega que "fue el riesgo generado por la negligencia omisiva del equipo médico y no otro, el que en definitiva se materializó, directa e inequívocamente, en el resultado de muerte de la criatura que llevaba la madre en su vientre, que es quién tiene la calidad de sujeto pasivo, no obstante que los hechos provocaron en la madre un síndrome angustioso depresivo, según se desprende de los documentos agregados a fs. 1,110 y 1.111 ".

El tratamiento conjunto del aborto con los delitos de homicidio se hace con base en el bien protegido que se afecta, la vida, y no por su consideración de delito "contra las personas", al ubicarse en otro título (del orden de las familias y la moralidad pública). Así, se rechaza el castigo penal de los abortos imprudentes y una interpretación que los considere dentro de los arts. 490-491, que sancionan supuestos imprudentes, aparece extensiva. Normalmente se ha entendido que la referencia a los delitos contra las personas remite a los tipos que se contemplan en el Título VIII del libro II que los trata, como en el caso de las agravantes de premeditación y de alevosía que se limitan a estos delitos (art. $12 \mathrm{No}_{\mathrm{s}} 1^{3}$ y 5). De todas maneras, esos delitos pueden interpretarse como aquellos en los que se afectan personas, sin restringirse a los contemplados en ese título. Se ha procedido de este modo frente a la agravante de astucia, fraude o disfraz, por no comprenderse la limitación a esos tipos ${ }^{4}$. Una interpretación similar se ha dado para la agravante de reincidencia específica del art. $12 \mathrm{~N}^{\circ}$ 16: los "delitos de la misma especie" se han entendido como los regulados

Cabe advertir que la Ley 20.480 que modifica el CP., y otras leyes, para la sanción de "femicidio" hace aplicable la alevosía para algunos delitos sexuales (art. 368 bis).

4 Politoff, Sergio / Ortiz, Luis (directores); Matus, Jean Pierre (coordinador) (2002).Texto y comentario del Código Penal chileno. Santiago: Editorial Jurídica de Chile, pp. 197 y 198. 
bajo un mismo título (a partir del art. 509 del CPrP), pero también los que afectan un mismo bien jurídico (desde el art. 351 del CPP). Entonces, ¿puede salvarse la extensión de la Corte? Para resolverlo se ha de tener presente algunas breves consideraciones sobre la interpretación en materia penal.

\section{1) INTERPRETACIÓN EXTENSIVA}

La interpretación extensiva supone aplicar una ley a un caso no contemplado explícitamente, a diferencia de la analógica, en la que el supuesto al que se pretende aplicar no está ni siquiera en forma implícita. Ambas se rechazan por el principio de legalidad ${ }^{5}$, pero varios autores han aceptado la extensiva mientras siga siendo interpretación, determine el alcance de la ley y se mantenga dentro de los términos que emplea ${ }^{6}$. Si cabe dentro de ellos no habría mayor problema. Se respeta el sentido literal de las palabras, que no procede respecto de la "interpretación" analógica, en cuanto suponga creación de delitos. De este modo, es interesante la concepción de persona que manejan las sentencias citadas, donde ese "otro" sujeto vivo también es el producto de la concepción: "La calidad de persona entonces, del 'otro' a que se refiere el Código Penal, no puede apreciarse con el rigor y criterios civilistas del entramado del Código Civil, así el Derecho Penal, en la salvaguardia de la vida humana, debe ir varios pasos más adelante para su debida protección por su condición de prevención y de prohibición, y si ocurre su quebrantamiento, debe propender a la inexistencia de la impunidad".

Relaciona el concepto de persona con el homicidio, ese "otro" que requiere el homicidio, y el aborto sería un homicidio, pues se mata a otro. Para ello se afirma también en un argumento sistemático, que como suele entenderse ha de servir de criterio auxiliar o complementario. La Corte Suprema cita, además de la CPR y de algunos tratados internacionales, la

5 En general, Politoff L., Sergio / Matus A., Jean Pierre / Ramírez G., María Cecilia (2003). Lecciones de Derecho penal chileno: Parte general. Santiago: Editorial Jurídica de Chile, pp. 99, 112, 114.

$6 \quad$ Cury Urzúa, Enrique (2005). Derecho penal: parte general. $7^{\text {a }}$ ed. Santiago: Ediciones Universidad Católica de Chile, p. 197, señala que si de la ley se deduce que se aplica a un mayor número de casos que los que aparecían en su consideración literal, nada obsta que se aplique a todos ellos, sin que importe una violación del principio de legalidad. "La interpretación solo interpreta no extiende ni restringe". Incluso acepta la interpretación analógica, en cuanto supone atribuir a un texto de significado dudoso, el mismo que se le otorga en otra u otras leyes, sobre todo cuando versan sobre el mismo asunto. Pero precisa que en caso de duda se ha de prescindir de la extensión sospechosa. Luzón Peña, Diego-Manuel (2002). Curso de Derecho penal: parte general I. Madrid: Universitas, pp. 170 y 171, incluso admite la "interpretación" analógica -distinta de la integración analógica cuando no hay disposición aplicable- mientras se mantenga dentro del "sentido literal posible" y, por ello, siga siendo interpretación. 
Ley No 20.120 de 2006 sobre la Investigación Científica en el Ser Humano, su Genoma, y Prohíbe la Clonación Humana. Su art. $1^{\circ}$ prescribe que "Esta ley tiene por finalidad proteger la vida de los seres humanos, desde el momento de la concepción, su integridad física y psíquica, así como su diversidad e identidad genética, en relación con la investigación científica biomédica y sus aplicaciones clínicas". En síntesis, esta “interpretación” es aceptable en cuanto se mantiene dentro del tenor literal, con auxilio de otros criterios interpretativos como el sistemático. Sin embargo, la argumentación de la Corte presenta otros problemas todavía dentro del tipo.

\section{2) OTROS PROBLEMAS DE FUNDAMENTACIÓN}

Por más seductora y aprobada que resulte la citada interpretación, ella se encuentra con otra "piedra de tope". Para incorporar el aborto dentro de los cuasidelitos de los arts. 490-492, relativos a los delitos contra las personas, se debe resolver una dificultad adicional a la discusión sobre la noción de "persona". El tipo de aborto habla de una causación maliciosa. Las palabras de la ley no solo limitan la conducta del agente a la acción, sino que exigen una determinada vinculación subjetiva, un conocimiento directo, un dolo directo, que impide la sanción de la imprudencia. Aceptarla, junto con excederse de la conducta típica, llevaría a admitir también injurias y calumnias imprudentes -además de la castración y las mutilaciones ${ }^{7}$-, porque esos tipos sí están contemplados como delitos contra las personas, aunque suponen un especial conocimiento de que se obra en deshonra o descrédito de otro. Tampoco convencen los otros argumentos de la Corte respecto de la tipicidad de la conducta. Por un lado, habla de una "negligencia omisiva" que afecta la salud de la madre y las lesiones graves solo se cometen por acción (art. 397), salvo la modalidad de suministro de sustancias o abuso de credulidad (art. 398). Por otro lado, no establece finalmente responsabilidad por lesiones imprudentes a la madre, pues concreta el riesgo creado en el resultado muerte de su hija no nacida, que se mantiene como víctima.

\section{3) PRinCipales DifiCUltades PARA ATRIBUiR RESPONSABILIDAD}

Las dificultades descritas se radican en la atribución de una conducta al tipo, su atribución típica. Sin embargo, los mayores problemas en la actividad médica no se producen con la tipicidad de resultados dañosos, donde se admite, por ejemplo, que en las operaciones quirúrgicas se cau-

De hecho, así se pronuncia la Corte de Apelaciones de Iquique. 27 de noviembre de 2007, Rol: 267-2007, que condena por mutilación imprudente de un seno en un contexto de cirugía estética por un profesional médico sin especialidad. Sin embargo, omitió un razonamiento mayor en torno al dolo. 
san lesiones ${ }^{8}$. La acción del médico que hace una incisión con un bisturí hiere a otro y calza con la descripción del legislador. Esta aceptación incluso se relaciona con una suerte de irresponsabilidad penal para quienes se desempeñan en este ámbito ${ }^{9}$, caracterizado por riesgos, por la posibilidad de que se produzcan daños. La consideración del riesgo genera la mayor dificultad a la hora de establecer la responsabilidad médica, que excede la mera descripción típica: qué riesgos se permiten y cuáles no.

Aquí se ha de retomar las últimas consideraciones de la Corte Suprema citadas: "fue el riesgo generado por la negligencia omisiva del equipo médico y no otro, el que en definitiva se materializó, directa e inequívocamente, en el resultado de muerte de la criatura que llevaba la madre en su vientre, que es quien tiene la calidad de sujeto pasivo, no obstante que los hechos provocaron en la madre un síndrome angustioso depresivo...”. Habla de la creación de un riesgo que se concreta en la muerte de la criatura no nacida. ¿Por qué se habla de la madre? Ahora, resulta además criticable la referencia a la madre como sujeto pasivo, en cuanto se afecta su salud y considere el riesgo de la "omisión" negligente del equipo médico respecto del resultado de muerte de la criatura no nacida. Los riesgos para los bienes jurídicamente protegidos y sus perturbaciones nos sitúan en otro plano, no tanto vinculado con la descripción legal, como con el objeto de la norma -qué se sanciona- y se enfrenta a las particulares características del ámbito médico. El caso que se comenta es paradigmático por la imputación de responsabilidad médica al extender los alcances de tipicidad, fuera de lo normalmente aceptado y con dudosa aprobación constitucional. Todavía para estas interpretaciones (si se acepta la doctrina de la Corte en este aspecto) y, por supuesto, para las que se mantienen dentro de los términos del legislador falta definir la atribución de riesgos y resultados jurídicamente relevantes, desde lo que la norma tutela, en una actividad especialmente compleja como la médica.

Sus características -asunción de riesgos para la vida y salud de las personas con fines curativos, así como el consentimiento de la víctima-paciente, conllevan la fijación del llamado "riesgo permitido", que complica determinar la afectación de un bien protegido: cuándo se afecta y cuándo

8 Puppe, Ingeborg (2007). "La justificación de la intervención médica curativa”. Traducción de Felip i Saborit, David. InDret, $\mathrm{N}^{\circ}$ 1, 14 pp., p. 3; Gómez Rivero, $\mathrm{M}^{a}$ del Carmen (2008). La responsabilidad penal del médico. 2a ed. Valencia: Tirant lo Blanch, pp. 256, 259, 260 y 265-326, acepta la vinculación con las lesiones tanto frente a la conducta del médico, como ante sus resultados. Expresa que los médicos "aunque 'lesionen' al paciente desde un punto de vista meramente descriptivo, no lo hacen en el sentido jurídico del término". Así lo destaca Künsemüller, Carlos (1986). "Responsabilidad penal del acto médico". Revista Chilena de Derecho. T. XIII, pp. 259-269, p. 262. Garrido Montt, Mario (1986). "Responsabilidad del médico y la jurisdicción". Revista Chilena de Derecho. T. XIII, pp. 281-288, p. 283, no es tan categórico y admite la responsabilidad médica desde tiempos remotos. No cuestiona su existencia, sino cuándo procede y cómo. 
tal perturbación se puede imputar a la conducta de un facultativo médico. ¿ Se puede hablar de un bien protegido en un ámbito que tolera ciertas actividades peligrosas por su utilidad o beneficio, con un fin de sanación o salvamento? ¿Cuando se realiza una conducta relevante penalmente, qué puede imputarse? Las respuestas son más difíciles aún si las conductas no son dolosas, sino imprudentes. La determinación de responsabilidad aquí se enfrenta a las dificultades de la noción de imprudencia, además de las inherentes a la actividad médica. Ellas se expondrán a continuación más allá del caso de aborto expuesto, para las figuras imprudentes en general que no suelen extender los alcances los tipos que se examinan ${ }^{10}$.

\section{2) Problemas FUndamentales DE LA LlamadA "IMPRUDENCIA MÉDICA”}

Las conductas imprudentes, a diferencia de las dolosas, no buscan los resultados dańosos producidos, sino que no siguen el cuidado necesario y debido para evitar esas consecuencias previsibles ${ }^{11}$. Si bien se han utilizado distintas denominaciones para fijar diversos conceptos de imprudencia ${ }^{12}$, ella apunta a una misma idea: una conducta activa o pasiva descuidada, que falta al cuidado debido. Pero ¿qué es el cuidado debido? ¿Cómo se relaciona con el resultado dańoso? La primera cuestión apunta

10 El límite se apoya en el sistema de incriminación de la imprudencia -que se sanciona excepcionalmente (arts. 4, $10 \mathrm{n}^{\circ} 13$ )-, además de los clásicos principios de subsidiariedad y ultima ratio. Aquí, es interesante la idea de gravedad que destaca Fernández Cruz, José Ángel (2002). "El delito imprudente: la determinación de la diligencia debida en el seno de las organizaciones". Revista de Derecho de la Facultad de Ciencias Jurídicas y Sociales de la UACH. T. XIII, pp. 101-121, pp. 104, 111-113, ya para tipificar las imprudencias.

11 Por ejemplo, la Corte de Apelaciones de Concepción. 5 de agosto de 2008, Rol: $951-$ 2007, señala: "Que en los delitos culposos se le reprocha al agente no haber observado en su comportamiento el cuidado requerido y exigible para evitar un resultado indeseable, no buscado, pero previsible para él en una situación concreta y que pudo haber sido evitado mediante una conducta más diligente".

12 Etcheberry, Alfredo (1986). “Tipos penales aplicables a la actividad médica”. Revista Chilena de Derecho. T. XIII, pp. 271-280, p. 271, distingue imprudencia, como creación o aumento de riesgos, de negligencia, que refiere a la omisión de medidas preventivas o neutralizadoras de riesgos. Nuestro CP. distingue niveles de imprudencia con términos diversos ("imprudencia temeraria", "negligencia culpable" y "mera imprudencia o negligencia", arts. 490-492) para sancionar de igual forma distintas situaciones, como lo hacía el CP. español. Hoy este Código solo habla de "imprudencia". Nino, Carlos Santiago (2006). Los límites de la responsabilidad penal. Buenos Aires: Astrea, pp. 418, 419, 424-432, utiliza los términos "imprudencia" y "negligencia" para distinguir entre la llamada culpa consciente e inconsciente. En la imprudencia se conocería el resultado como probable y en la negligencia no, aunque sí reconoce alguna vinculación subjetiva en ciertas negligencias (infra, nota 60). En el Derecho anglosajón se hace una distinción similar: recklessness y negligence. La primera implica conciencia de riesgo, mientras que en la segunda falta. Ver Alexander, Clarence (1949). The Law of arrest in criminal and others proceedings. Buffalo, N. Y: Dennis \& Co. Vol. 2, pp. 1767, 1771 y 1772. 
a la misma noción de imprudencia y la segunda a su imputación frente a las consecuencias por las que se ha de responder si corresponde. Desde su definición, la imprudencia parece no tener que ver con la tipicidad solamente, pues faltar a un deber de cuidado implica infringir una norma de cuidado. Se determina como un concepto normativo que se vincula con lo antijurídico o injusto ${ }^{13}$. Afecta una norma jurídica, pero no quiere decir que no tenga relación con la tipicidad. El tipo describe supuestos imprudentes en abstracto y la tipicidad también supone valoraciones a la hora de atribuir conductas al tipo, solo que a nivel general ${ }^{14}$. La separación de niveles de enjuiciamiento solo procede si se acepta la distinción entre tipicidad y antijuridicidad. Por eso conviene primero precisar lo injusto penal y la relación entre esas categorías (tipicidad y antijuridicidad), para luego revisar cuándo una conducta falta al cuidado debido y puede imputarse penalmente. Para ello, se requiere definir previamente la noción de injusto que se toma como base de análisis. A partir de allí se examinarán las dificultades de imputación del comportamiento y del resultado injusto.

No es fácil establecer una falta al cuidado debido y cuando se determina no siempre cabe hacer responsable al médico que realiza esa conducta "peligrosa" si el resultado dańoso se produce por un comportamiento ajeno, por ejemplo, un médico cirujano puede no emplear el cuidado debido en su intervención y posteriormente se sume la conducta inadecuada o indebida del anestesista o de la enfermera, etc. ¿A quién se imputa la muerte? No solo importa determinar las conductas por las que se ha de responder, sino también por qué resultados. La responsabilidad penal exige la imputación objetiva de la conducta y del resultado.

Otro problema aparece con la misma noción de imprudencia. Su determinación normativa cuestiona la calidad subjetiva de este tradicional "elemento subjetivo". ¿Qué queda de subjetivo? La conducta no se atribuye solo objetivamente. Afirmar lo contrario no parece coherente frente a la estructura del comportamiento de una persona humana. La noción de norma no se desvincula del comportamiento, es este el que se juzga como

13 Ver Garrido Montt (1986) 287. Esta definición normativa lleva a Goldschmidt, James (1913). "Der Notstand, ein Schuldproblem". Österreichische Zetschrift für Strafrecht. No 4 , pp. 129-196, a "adelantar" la imprudencia desde el juicio de culpabilidad al injusto. CorCoy Bidasolo, Mirentxu (2005). El delito imprudente. 2a ed. Montevideo-Buenos Aires: B de F, pp. 7, 27, 28, 55, 103, 104, 106, se remite al injusto que, sobre una norma de determinación, integra solo con el desvalor de acción. Hava García, Esther (2001). La imprudencia médica. Valencia: Tirant lo Blanch, pp. 49, 52, expresa que la infracción de la norma de cuidado constituye el desvalor de acción, pero precisa que es uno de los tres elementos de la imprudencia. Suma la previsibilidad objetiva del resultado y el resultado objetivamente imputable que conforma el desvalor de resultado.

14 La antijuridicidad supone una valoración más concreta. Hava García (2001) 39, aunque habla de una "peligrosidad estadística", alude a la infracción de concretas normas de cuidado. 
jurídico o antijurídico. Claro que las respuestas serán diferentes según la noción de norma que se tenga. Las calificaciones son complejas tanto en el ámbito objetivo como en el subjetivo. Interesa aquí observar a grandes rasgos, por los límites de esta exposición, dos problemas: ¿Qué es lo injusto penal en la imprudencia médica y cómo se imputa?

\section{3) ASPECTOS GENERALES DE LO INJUSTO PENAL}

Es necesario recordar que toda decisión depende del punto de partida que se tome. Así, también ocurre con la construcción y contenidos de las diversas categorías del delito. Por eso es importante precisar la perspectiva de análisis y las bases del examen que aquí se realiza. Para enfrentar el problema de lo injusto penal, se comenzará por aspectos generalmente aceptados. De un lado, el tipo es la descripción del supuesto de hecho que hace el legislador y la tipicidad es la característica de una conducta que calza con el tipo. De otro lado, la antijuridicidad se considera un juicio valorativo que recae sobre la conducta en cuanto es contraria a Derecho y lo antijurídico o injusto es la misma conducta infractora, lo desvalorado. Normalmente, se entiende que una conducta antijurídica es contraria a Derecho al lesionar o poner en peligro un bien jurídico penal. En este sentido se habla de antijuridicidad material. Aquí ya se incorpora elementos discutibles a la noción de antijuridicidad, como el bien jurídico penal. De modo que procede realizar algunas precisiones terminológicas.

\section{1) PRECISIONES TERMinOLÓGICAS}

En general, se distingue la antijuridicidad formal de la material15, a pesar de que no se le atribuye mayor relevancia. Formalmente, se concibe como contrariedad al Derecho, al ordenamiento jurídico. Por su parte, la antijuridicidad material se representa como perturbación o afectación de bienes jurídicos penales, de situaciones tuteladas por la norma jurídica penal. Como la antijuridicidad formal apunta a la contradicción genérica de la conducta con el Derecho, se tiende a verificar con la ausencia de causas de justificación. La antijuridicidad material, en cambio, exige la afectación de aquello protegido por la norma, del bien tutelado. Esta última idea es particularmente importante frente al concurso de delitos, que se muestra incluso respecto de bienes colectivos, como en una sen-

15 En general, Roxin, Claus (1997). Derecho penal: Parte general. Traducción de la 2a ed. alemana de D. Luzón Peña; M. Díaz y García Conlledo; J. de Vicente Remesal. Madrid: Civitas, pp. 558-562. 
tencia de la Corte de Apelaciones de Rancagua que se pronuncia sobre porte y tenencia ilegal de armas ${ }^{16}$. Entiende que ambas conductas afectan el mismo bien jurídico, la seguridad pública, aunque conforman dos actos típicos separables intelectualmente. Sostiene que el porte ilegal engloba el desvalor de la tenencia pues implica mayor "peligrosidad", que la "antijuridicidad material no aumenta un ápice porque esa arma no esté inscrita". "Una antijuridicidad material ha englobado a la otra". El ataque contra el bien jurídico es único, un solo peligro.

Si bien se ha dejado de lado esta distinción, tiene relevancia frente a la idea de imputación de injusto y a la relación entre tipicidad y antijuridicidad que se toman para examinar las cuestiones de imputación que se plantean. Este aspecto material parece requerir más que la contrariedad genérica de la norma, un examen más concreto de la lesividad o dañosidad de la conducta. En este sentido, se parte de una noción integral de norma penal que comprende tanto determinaciones como valoraciones ${ }^{17}$, determinaciones que se dirigen a los hombres pues se valoran ciertos estados y se desvaloran otros. Sucede que la antijuridicidad surgió formal como contradicción a la orden jurídica y está volviendo a ese carácter, como en tesis funcionales, que pretenden satisfacer lo injusto con una contradicción genérica de la norma penal construida como norma de de-

16 Corte de Apelaciones de Rancagua de 23 de abril de 2004, Rol: 217.637.

17 Hruschka, Joachim (1994). "Reglas de comportamiento y reglas de imputación". Traducción de F. Baldó Lavilla. Anuario de Derecho Penal y Ciencias Penales. Vol. XLVII. Fasc. III, pp. 343-356, p. 345, destaca la doble calidad de las reglas de comportamiento, como dos caras de una moneda, con dos funciones: la configurativa desde una perspectiva prospectiva y la de baremo de medición desde una perspectiva retrospectiva. Aclara que en esta última perspectiva las reglas llevan valoraciones de las que resulta la antijuridicidad de la conducta, que distingue de las reglas de imputación. También KindhäUser, Urs (2008). "El tipo subjetivo en la construcción del delito". InDret, $\mathrm{N}^{\circ}$ 4, 35 pp., p. 8, separa norma de reglas de imputación y concibe lo antijurídico con determinaciones y valoraciones. Semejante distinción de reglas (conducta e imputación) lleva a FrIsCH, Wolfgang (2009). "Lo fascinante, lo acertado y lo problemático de la teoría de la imputación objetiva del resultado” en Sancinetti, Marcelo (compilador): Causalidad, riesgo e imputación. Buenos Aires: Hammurabi, pp. 345-381, pp. 373, 379-380, a considerar la creación de un riesgo prohibido como la conducta prohibida y no como criterio de imputación. Mañalich, Juan Pablo (2010). "Norma e imputación como categorías del hecho punible". Revista Estudios de la Justicia. N ${ }^{\circ} 12$, pp. 165-185, pp. 170, 172, 173, además de distinguir normas de reglas de imputación, siguiendo a Wittgestein, separa el contenido de la norma de sus funciones. Afirma que el criterio teleológico de legitimación de la norma de comportamiento es la protección de bienes jurídicos y que es irrelevante que se aplique como norma de determinación o de valoración porque tiene funciones de prospección y retrospección. Este reconocimiento complica de todas formas la distinción con las reglas de imputación. Así, señala que por la imputación "el hecho punible se constituye como contradicción de la norma", como injusto (pp. 174 y 176). Respecto de la inclusión de valoraciones, interesa la advertencia de GARCíA-PABLOS DE Molina, Antonio (2006). Introducción al Derecho penal. 4a ed. Madrid: Ramón Areces, pp. 88 y 91-93: el Derecho penal no solo sanciona o refuerza un orden jurídico preexistente, sino que lo crea y tiene criterios propios según su misión. No interesa la obediencia por la obediencia, sino en cuanto esa misión se cumpla. 
terminación. La pena vendría solo a confirmar que aquella sigue vigente. Se evita hablar de perturbación de bienes jurídicos aunque no se deja de lado la idea de fin de la norma. Reconocer que esta tiene o, mejor, que cumple funciones no significa que esté privada de contenido. De allí que uno de los principales exponentes de este pensamiento no deje de lado la noción de bien, aunque lo identifique con una expectativa, una pretensión de respeto ${ }^{18}$. ¿Qué se respeta? "Algo" se respeta ${ }^{19}$. Las expectativas o pretensiones no eliminan contenidos; sino que su formulación no los considera, a diferencia de una concepción global de norma que integra valoraciones. Schüneman ${ }^{20}$ se refiere expresamente a la introducción de valoraciones en una normativización "complementaria" y no excluyente, que no ignora la realidad social.

Como se observa, las decisiones de antijuridicidad dependen de qué se entienda por bien jurídico y, más bien, qué noción de norma penal se tenga o mantenga. Esta discusión puede remontarse a la distinción entre ley penal y norma penal, que desde Binding ${ }^{21}$ impera en nuestra dogmática jurídica. El hecho de cumplir la ley penal no significa que se esté infringiendo la norma penal. Aquí comienzan las diferencias: la relación entre tipicidad y antijuridicidad.

\section{2) RELACIÓN TIPICIDAD Y ANTIJURIDICIDAD}

Un estudio relativamente serio que se aproxime a lo injusto, aun para cuestionar su atribución, no ha de eludir su integración y, básicamente, la relación entre las categorías que lo constituyen, la tipicidad y la antijuridicidad. La doctrina nacional entiende normalmente que la tipicidad es indiciaria de la antijuridicidad ${ }^{22}$. Una conducta que calza con los elemen-

18 Jаковs, Günther (2001). ¿Qué protege el Derecho penal: bienes jurídicos o la vigencia de la norma? Traducción de Manuel Cancio Meliá. Mendoza: Ediciones Jurídicas Cuyo, p. 18, señala que el bien aparece como pretensión de su titular para que sea respetado. Afirma así que no es un objeto físico, sino que ha de representarse como norma, como "expectativa garantizada".

19 Bustos Ramírez, Juan (2007). Obras completa. 2a ed. Santiago: EJS. T. II, pp. 82 y 83, expresa que el contenido de las normas no surge de ellas sino de "valoraciones de algo en referencia”, el bien jurídico.

20 Schünemann, Bernd (2009). Obras. Santa Fe: Rubinzal-Culzoni Editores. T. I, p. 339.

21 Binding, Karl (1922). Die Normen und ihre Übertretung. Frankfurt del M.: Liepzig. Vol. I (reimp., Aalen, Hamburg, 1991), pp. 132 y ss.

22 Etcheberry, Alfredo (2001). Derecho penal: parte general. $3^{a}$ ed. Santiago: Editorial Jurídica de Chile. T. I, p. 238; Politoff / Matus / Ramírez (2003) 211; Politoff Lifschitz, Sergio (2002). " $\$ 2$. De las circunstancias que eximen de responsabilidad criminal: Comentario preliminar al art. 10" en Politoff Lifschitz, Sergio / Ortiz Quiroga, Luis (directores); Matus Acuña, Jean Pierre (coordinador). Texto y comentario del Código Penal chileno. Santiago: Editorial Jurídica de Chile. T. I, 93-100, p. 96; Bustos Ramírez, Juan (1989). Manual de Derecho penal: Parte general. $3^{a}$ ed. Barcelona: Ariel, p. 159. En la doctrina extranjera, Jаковs, Günther (1995). Derecho penal parte general, fundamentos y teoría de la 
tos del tipo es un indicio de que está prohibida por el Derecho, de que se infringe la norma penal, porque generalmente es así. Esa infracción de la norma penal se suele representar como lesión o peligro para el bien que tutela. Es tan estrecha la relación entre ambas categorías que muchos autores, sobre todo espańoles y alemanes ${ }^{23}$, consideran que la tipicidad supone la antijuridicidad. No las distinguen realmente, pues existiría un solo gran juicio valorativo sobre la conducta. En este sentido, destaca la teoría de los elementos negativos del tipo. Una conducta sería típicamente antijurídica si además de cumplir con los elementos del tipo, coincidir con el supuesto de hecho descrito por el legislador, no existen causas de justificación. Los elementos negativos del tipo apuntan a la falta de causas de justificación. Si ellas existen, la conducta no sería típica y no solo jurídica o justificada.

Se podría pensar que no es tan relevante la discusión sobre si se consideran elementos negativos del tipo o si se contemplan como causas que excluyen la antijuridicidad de la conducta ya típica porque en cualquier caso no se ha de aplicar una pena. Sin embargo, tiene repercusiones. Las causas de atipicidad no son iguales que las causas de justificación o juridicidad y afirmar la tipicidad de una conducta no supone afirmar su antijuridicidad. Corresponden a dos niveles de valoración diferentes que atienden a diversos parámetros y su identificación puede llevar a confusión. No necesariamente porque se cumpla la ley penal, realizándose el tipo, la conducta va a ser antijurídica aunque falten causas de justificación. Su equivalencia podría suponer una afectación inmediata. Es fundamental la infracción real de la norma. La identidad o unificación puede llevar a "formalizar" el juicio de atribución, sin que interese perturbación alguna. Así, podría entenderse que la sola incisión que realice un médico con un bisturí provoca las lesiones y muerte del paciente, sin averiguar otros antecedentes sobre la afectación de su salud y vida, o el fin de la norma, por tal conducta.

El mismo Jakobs ${ }^{24}$ entiende que la distinción de categorías -también de la culpabilidad-importa no tanto por motivos didácticos, como por su necesidad: porque cada una de ellas (presupuestos de imputación) depende de la existencia de otras. Critica la teoría de los elementos negativos del tipo, pues la falta de causas de justificación no obedece a elementos negativos ${ }^{25}$. Estos elementos explican la consideración negativa de la conducta y que la ley las castigue porque ellos faltan. Tienen que estar

imputación. Traducción de J. Cuello; J. Serrano. 2a ed. (alemana). Madrid: Marcial Pons, p. 195.

23 Así, principalmente Merkel, Adolf (1889). Lehrbuch des deutschen Strafrecht. Stuttgart, $\mathbb{S}$ 30, p. 82.

24 Jаковs (1995) 188.

25 Jаков (1995) 193. 
ausentes para que la conducta sea típica y proceda el castigo si se dan los demás elementos del delito. En cambio, la inexistencia de normas permisivas explica la sanción no por una especial consideración de tal ausencia, como lo serían "sin la voluntad" o "sin derecho", sino porque no existe un contexto especial que haga tolerable la conducta anómala. Esta es en general anómala. Por eso, para constatar la antijuridicidad de la conducta habla de otro "paso mental" al de la tipicidad, un "escalón" de la comprobación del delito ${ }^{26}$. Con esta distinción, se comparte la solución de Jescheck $^{27}$ en cuanto las circunstancias de hecho que hacen aparecer la conducta como reprochable son del tipo y su valoración "como medida de su crecida reprobabilidad" pertenece a la antijuridicidad. Ello, sin perjuicio de que la atribución de una conducta al tipo ya implique valoraciones con relación a la descripción del legislador (generales).

Por ahora, es fundamental tener en cuenta que la antijuridicidad nace como categoría penal frente a la idea de infracción de norma y que su desarrollo está íntimamente ligado a la noción que de esta se tenga. Si la antijuridicidad determina una conducta contraria a la norma o al ordenamiento jurídico, no cabe una real separación entre antijuridicidad formal y antijuridicidad material; ello no puede ser formalmente contraria a la norma si no se afecta realmente su contenido. Pueden distinguirse conceptualmente, pero una conducta no puede ser antijurídica formalmente y jurídica materialmente ni viceversa. Se sigue así a Molina Fernández ${ }^{28}$ con su tesis de la "correspondencia": no son aspectos diferentes, sino dos perspectivas de una única antijuridicidad. Así, "la acción formalmente prohibida lo está por tener un contenido material disvalioso: por lesionar o poner en peligro algún bien que el legislador ha estimado merecedor de protección”. De suerte que la tipicidad supondrá un primer juicio de atribución genérico, frente a la descripción del legislador, y la antijuridicidad una apreciación más concreta que se vincula con el objeto de la norma y, con ello, lo injusto tiene un contenido material.

Con esta determinación general, procede examinar qué ocurre con la imputación del injusto en la imprudencia médica. ¿Cuándo una conducta y un resultado pueden imputarse en este ámbito? Estas cuestiones se plantean a continuación a grandes rasgos y frente a ciertos problemas prácticos.

ЈаковS (1995) 195.

Jescheck, H-H / Weigend, T. (2002). Tratado de Derecho penal. Parte general. Traducción de Miguel Olmedo Cardenete. 5a ed. Granada: Comares, p. 265.

28 Molina Fernández, Fernando (2001). Antijuridicidad penal y sistema del delito. Prólogo de Gonzalo Rodríguez Mourullo. Barcelona: J.M. Bosch, pp. 45-58. 


\section{4) DifiCUlTadeS DE DETERMINACIÓN E IMPUTACIÓN DEL INJUSTO PENAL DESDE EL ÁMBITO MÉDICO}

Es particularmente complejo fijar lo antijurídico en el ámbito médico por los riesgos inherentes y las finalidades que se persiguen. Los resultados lesivos son frecuentes y las actividades se realizan igualmente por los beneficios que se esperan: básicamente, curar y precaver enfermedades. Los riesgos de daños se asumen por esos beneficios. Así, ellos se toleran y se determina un sector de riesgo permitido, donde el mismo consentimiento del paciente-víctima tendrá un especial rol ${ }^{29}$. La producción de daños no generará responsabilidad $p e r s e^{30}$. Es necesario que esas consecuencias excedan el ámbito de lo permitido y puedan imputarse al facultativo médico. Al establecer esta responsabilidad, nuestros tribunales suelen enumeran requisitos sin mayor explicación y orden ${ }^{31}$. Se entiende que debe haber una conducta, un resultado, infracción a la lex artis y previsibilidad del resultado. Algunos agregan la causalidad o la sustituyen por la previsibilidad o la contravención de la lex artis. Por ejemplo, la Corte Suprema, en un pronunciamiento de 15 de septiembre de 2008 (Rol: 7070-2007), realiza una exposición semejante: comportamiento voluntario; "resultado antijurídico"; previsibilidad del resultado; obligación de preverlo y relación causal entre la conducta y el "resultado típico". Luego parece catalogar los requisitos cuando los resume en dos pilares: el deber de cuidado y la previsibilidad.

Esos dos elementos parecen cimentar la imprudencia, pero, hasta ahora, no está muy claro cómo. La sola producción de resultados dańosos no hace responsable penalmente al facultativo médico. Es necesario examinar su conducta y la relación que existe con el resultado. El ámbito de riesgo en el que se desenvuelve este profesional complica tanto la atribución de semejantes efectos, como la imputación de la misma conducta que genera el peligro. Estas dificultades pueden llevar a la total irrespon-

29 Puppe (2007) 4 y ss., destaca el consentimiento del paciente frente a la decisión de los riesgos que se asumen como menores dentro de un contexto de justificación por el estado de necesidad que involucra. No es un consentimiento aislado. Por eso señala que no solo excluye el injusto, sino que ni siquiera permite que aparezca. Por supuesto, la validez del consentimiento depende de la información dada. En nuestro país, Rodríguez Peña, Pilar (2010). "El consentimiento al acto médico. Una mirada comparada entre el Derecho francés y chileno". Revista de Derecho y Ciencias Penales de la Universidad San Sebastián. No 14, pp. 33-44, pp. 34 y ss., habla de un consentimiento previo obligatorio y lo conecta con la dignidad de persona.

30 La producción de daños no se considera suficiente incluso en caso de fallos técnicos, que pueden no ser imputables. Así, Künsemüller (1986) 266, distingue su existencia de su valoración jurídico-penal.

31 Por ejemplo, Corte Suprema. 22 de julio de 2009. Rol: 5575-2008; Corte de ApelacioNes De Concepción de 5 de agosto de 2008, Rol: 951-2007; Corte Suprema. 23 de abril de 2007. Rol: 6585-2006. 
sabilidad penal aunque se lesione al paciente, pero también podrían, por el contrario, suponer una responsabilidad por resultados. Para evitar estos extremos y facilitar la resolución de casos, se examinan los problemas más relevantes con relación a la imputación de la conducta y del resultado en intervenciones médicas imprudentes, sobre todo quirúrgicas, pues únicamente cuando existe un "diagnóstico" procede dar un "tratamiento".

\section{1) IMPUTACIÓN DE LA CONDUCTA}

En general, las consecuencias producto de intervenciones médicas no generan responsabilidad si se mantienen dentro de los parámetros aceptados. Un comportamiento tendrá relevancia cuando exceda o sobrepase los límites de lo permitido y cree un riesgo prohibido que permita su imputación. Si ella cumple con el cuidado debido se mantiene dentro del margen autorizado y si no lo sigue o lo supera crea un riesgo relevante. El problema es, ¿qué es el cuidado debido? La norma de cuidado no está expresamente descrita y su determinación se deja al juez ${ }^{32}$. Ella puede deducirse del ordenamiento jurídico, la ley y las normas. Tiene límites. El primero es lo que dice el legislador, el tipo penal: la conducta y el resultado, conforme a los que procede el juicio de tipicidad. Luego se ha de examinar el caso concreto frente al contenido de la norma primaria que se colige de la ley penal y también de otras reglas y criterios extrapenales que pueden provenir de regulaciones expresas como las normas del tránsito o pueden estar inmersas en la propia actividad de que se trata, como la conocida lex artis. Ellas permiten determinar el cuidado que se debe emplear en cada caso, la norma de cuidado, y cuándo se infringe, al sobrepasar los límites de lo permitido que hacen imputable objetivamente la conducta al injusto.

\section{(4.1.1) Determinación del deber de cuidado}

Para la determinación del cuidado debido en la actividad médica, además de las normas generales que protegen la vida y salud de las personas, destaca precisamente la lex artis como conjunto de principios y reglas técnicas propios del arte de la medicina, vigentes al momento de actuar. Sirve de guía para establecer la norma de cuidado en la situación concreta. De allí que cuando no se siguen esos parámetros se falta a dicha norma y la conducta es imputable. Es tal la guía, que en la práctica se es-

32 Cury Urzúa, Enrique (1981). "Contribución al estudio de la responsabilidad médica por hechos culposos". Revista de Ciencias Penales. T. XXXVII (1978-1981), 97-105, pp. 99 y ss., destaca que en este proceso es inevitable cierto grado de incertidumbre, pues depende del "modo de deducir" del juzgador. 
tablece como "fundamento" de la imprudencia médica ${ }^{33}$. Normalmente se habla de una "culpa media", con un estándar de cuidado medio, por los términos del artículo 491 del CP.: "negligencia culpable" 34 . Incluso se ha aumentado el nivel de cuidado al considerarla como reglamentos que si se infringen permiten sancionar por "mera imprudencia o negligencia" según el art. $492^{35}$. Independientemente que estas reglas del arte médico aparezcan en protocolos (codificados o no), son parámetros flexibles que concurren a determinar el cuidado debido según las circunstancias, que no fijan un cuidado excesivo y determinan responsabilidad por culpa leve, ni establecen un cuidado mínimo que haga responsable por culpa grave. La posición de garante del facultativo médico exige que ponga todos los medios que tenga a su disposición dentro de los límites de su propia actividad $^{36} \mathrm{y}$, dentro de estas condiciones, la lex artis establece exigencias medias, reglas para la conducta profesional media, según las circunstancias del caso concreto.

De todas formas, los estándares de cuidado no son fáciles de fijar por las distintas circunstancias fácticas y personales, las condiciones de los establecimientos hospitalarios, los recursos técnicos y administrativos, los conocimientos y capacidades del médico, etc. A la determinación del deber de cuidado se suma la dificultad para precisar el contenido de esta lex para fijar los límites de lo debido. Los constantes cambios que se producen en este ámbito pueden exigir que en el caso específico no se sigan las reglas aceptadas hasta ese momento y no solo por avances técnicos, sino también por las circunstancias particulares, como las características del paciente o el ambiente en el que se actúe. Por eso se habla de una "lex artis ad-hoc", que cambia en la situación que se examina, por lo que el incumplimiento de la lex artis general no suponga una falta del cuidado debido $^{37}$. En este sentido se puede hablar de una concreta norma de cuidado, según el caso. Para apreciar estas reglas técnicas y establecer el núcleo

33 Así, Corte Suprema. 19 de enero de 2005. Rol: 9-2003; CS. Rol: 6585-2006; C. De Ap. De Santiago. Rol: 6974-2005.

34 La falta de calificativos como "temeraria" o, por el contrario "mera" negligencia, que utilizan las otras disposiciones que sancionan la imprudencia en los delitos contra las persona, no muestra una exigencia particular, mayor o menor a la normal o media. De todas formas se ha criticado el agregado de "culpable", por redundante -si se alude a la falta de cuidado-o por innecesaria si se trata de la imputación personal -necesaria en todo delito-. Así, ETCHEBERRy (2001) 318 y 319.

35 Por ejemplo, Corte Suprema. 4 de junio de 2008. Rol: 434-2008.

36 Por las características de esta actividad, la obligación de quienes aquí se desempeñan es de medios y no de resultados. Cierta discusión existe respecto de actividades innecesarias como la cirugía plástica. Ver Fernández Hierro, José Manuel (19998). Sistema de responsabilidad médica. 2a ed. Granada: Comares, pp. 55-64.

37 Se apoya también en la libertad del médico para la elección del tratamiento según un principio "in dubio pro libertate" como lo explica, Silva SÁnchez, Jesús-María (2001). "Libertad de terapia e imprudencia médica". Revista Peruana de Doctrina y Jurisprudencia Penales. $\mathrm{N}^{\circ}$ 2, pp. 549-588, 554 y ss. 
de la norma de cuidado $\mathrm{HAvA}^{38}$ introduce una idea clave: "neutralizar" focos de peligro existentes o de impedir la creación de nuevos riesgos.

\section{(a) El problema de los conocimientos especiales del médico}

Corcoy ${ }^{39}$ aclara que las reglas técnicas sirven como baremo para la determinación del cuidado debido y que no implican aún infracción de la norma de cuidado. Otra cosa es que para determinar esta infracción se ha de tener claro el deber de cuidado. En esta precisión se presenta el problema de la influencia de los conocimientos y capacidades especiales del médico. Si tales capacidades se dejan fuera de la norma de cuidado, un médico particularmente experto que no haga uso de ellas y provoque la muerte o lesión del paciente no creará un riesgo prohibido si cumple la norma de cuidado que se establece por parámetros medios. Esos conocimientos no tienen relevancia para el contenido injusto de la conducta. Algunos entienden si fijan el concreto deber de cuidado y se consideran, por tanto, en el nivel de lo injusto ${ }^{40}$. Ese médico experto tendrá un deber de cuidado específico. Esta comprensión resulta interesante desde que no dejará libre al experto que no utiliza sus conocimientos y capacidades especiales, a pesar de que cumpla según parámetros objetivos de un "médico medio". Sin embargo, impacta cuando se observa que se cumple la lex artis común y que la inclusión de esos conocimientos supondría exigencias más altas en ciertos casos. Existe un problema de desigualdad, pero la mayoría discute semejante incorporación básicamente porque confunde la antijuridicidad con la culpabilidad ${ }^{41}$. Ahora, ya no se trata de la relación

Hava García (2001) 55.

Corcoy Bidasolo (2005) 76, 79, 86, 87, 100.

Cramer $\$ 15$. En Schönke, A. / Schröder, H. (2006). Strafgesetzbuch Kommentar, nm 118 ss.; Roxin (1997) 1015-1018. Corcoy Bidasolo (2005) 98, 103-110, 122, 123, equipara conocimientos especiales con capacidades y considera que ambos condicionan la peligrosidad objetiva de la conducta. Hava García (2001) 71, 72, sigue esta línea. Entiende que existen distintas normas de cuidado para un profesional médico con menos capacidades y para otro con más experiencia y conocimientos. Sin embargo, conecta también esta problemática con los delitos de omisión para establecer la creación de riesgos imputables. En similar sentido, Stratenwerth, Günter (2005). Derecho penal. Parte general I. Traducción de Manuel Cancio Meliá; Marcelo Sancinetti. 4a ed. Buenos Aires: Hammurabi, p. 505, aunque luego precisa los límites de las capacidades en lo injusto. VAN WeEzel, Alex (2008). Pena y sentido. Estudios de Derecho penal. Lima: Ara, pp. 177, 185-189 y 193, considera los conocimientos y capacidades especiales para determinar el deber de cuidado y no fraccionar la noción de imprudencia, pero limitará tal inclusión frente a la confusión entre deber y poder. Distingue entre la materia de lo jurídicamente debido en el tipo y las condiciones de las exigencias jurídicas en la culpabilidad.

41 Struensee, Eberhard (1991). "Atribución objetiva e imprudencia”. Cuadernos de Política Criminal. No 44, pp. 449-458, pp. 450 ss. Cerezo Mir, José (2008). Derecho penal: Parte general. Montevideo - Buenos Aires: B de F, pp. 471-473, 475, 476, critica la inclusión de capacidades especiales y las separa de los conocimientos especiales que sí considera relevantes para el deber objetivo de cuidado, pues se incluyen en la situación del autor y del caso 
entre las categorías que integran lo injusto, tipicidad y antijuridicidad, sino que se extiende a la imputación personal: no solo si, por ejemplo, el médico hiere a otro con un bisturí y afecta la vida jurídicamente protegida, sino si el especialista está jurídicamente obligado a evitar tal lesión, en cuanto podía y debía cumplir la norma. La confusión se suele resolver recurriendo a la omisión ${ }^{42}$, si se establece una posición de garante de la indemnidad del bien que está bajo su cuidado, existe una fuente de peligro cuya realización en el resultado depende de la conducta del profesional médico. En estos casos la creación de un riesgo relevante, por sobre el nivel permitido, puede incluso ser dolosa, es decir, puede conocerse y buscarse. El problema de esta solución, si se conserva un criterio objetivo para medir el cuidado debido, es que parece mantener un parámetro distinto: los conocimientos y aun capacidades especiales del médico tendrían relevancia para la omisión y no para la acción, donde bastaría el criterio objetivo general ${ }^{43}$.

Jorge Barreiro ${ }^{44}$ también alude a la omisión, pero no deja de considerar aspectos subjetivos en la determinación del deber de cuidado objetivo. Siguiendo a Welzel, señala que este deber se define tanto por la

concreto. Fernández Cruz (2002) 110 y 111, rechaza esta inclusión para determinar el deber de cuidado, que ha de tener una "naturaleza objetiva y general". Distingue, adecuadamente, como otra situación el no estar en condiciones de comprender el deber objetivo de cuidado. Parece separar este aspecto subjetivo, pero no es tan claro cómo ni dónde lo ubica cuando, por otro lado, afirma que la previsibilidad del resultado se ha de situar en la imputación personal y en el tipo (p. 109). ¿Qué se considera y dónde?

42 En los términos de Silva Sánchez, Jesús-María (1986). El delito de omisión. Concepto y sistema. Barcelona: Bosch, pp. 122, 135-137, 146, 147, 206, 207, con relación a "expectativas de protección de bienes jurídicos" y a deberes de actuación prudente en situaciones peligrosas, como también lo expresan Jescheck / Weigend (2002) 624 y 625. Schaffstein, Friedrich (2009). "Disvalor de acción, disvalor de resultado y justificación en los delitos imprudentes" en Sancinetti, Marcelo (comp.): Causalidad, riesgo e imputación. Buenos Aires: Hammurabi, pp. 217-243, pp. 218 y 219, describía así el núcleo de los tipos imprudentes, con relación al riego para bienes jurídicos ajenos dentro de un determinado ámbito de relación. Јаковs, Günther (1996). La imputación objetiva en el Derecho penal. Buenos Aires: Ad-Hoc, pp. 56, 65, 104 y 105, acude a argumentos relativos a la posición de garante justamente para actividades riesgosas como la conducción de vehículo. En nuestro país, VAN Weezel, Alex (1999). "Parámetros para el enjuiciamiento de la infracción al deber de cuidado en los delitos imprudentes". Revista Chilena de Derecho. № 2. Vol. 26, pp. 323-336, pp. 325, 334 ss., critica esta subjetivación de la previsibilidad objetiva y recurre a la omisión, aunque más tarde la propondría de otra forma según se expone en la nota siguiente.

43 Van Weezel (2008) 180, 188, objeta la solución dominante de la omisión, al suponer dos conceptos de imprudencia. Propone resolver el problema con una noción unitaria de imprudencia que incluye conocimientos y capacidades especiales, pero no deja de lado la omisión. Acude a la idea de la verdadera omisión de las medidas de cuidado para configurar el injusto imprudente, que se determina con consideraciones individuales (pp. 187, 189). Advierte que su solución no funciona en todos los casos, sino cuando el deber de cuidado se concreta en un "deber de actuar prudentemente en situaciones peligrosas" (pp. 190 y 191), sin que se distinga demasiado de las tesis que remiten a la omisión.

44 Jorge Barreiro, Agustín (1990). La imprudencia punible en la actividad médico-quirúrgica. Madrid: Tecnos, pp. 43, 65 y 66. 
creación de un riesgo para bienes jurídicos, como por la previsibilidad objetiva del resultado. Con esta previsibilidad se está aludiendo a una vinculación subjetiva, que aparece como otra forma de relación entre conducta y resultado. De todas formas, una previsibilidad objetiva con el parámetro del "médico medio" no toma en cuenta en realidad la situación del específico médico en el caso concreto, a pesar de que este mismo autor destaca la necesidad de determinar el cuidado debido frente a las circunstancias de tiempo y lugar, así como las del médico, quien tendría el "deber" de examinar su propia capacidad antes de actuar ${ }^{45}$. El examen general del cuidado debido no agota su precisión, pues solo corresponde a una primera apreciación de la conducta según el supuesto descrito en el tipo penal, pero no es suficiente para determinar lo injusto según la relación entre tipicidad y antijuridicidad y la idea que de esta última se sigue (una correspondencia entre lo formal y lo material). Se requiere un examen más concreto al enfrentar el contenido normativo, qué se protege y cómo se afecta ${ }^{46}$, que excede la investigación del deber objetivo de cuidado dentro de los parámetros del hombre medio.

Apreciar la situación concreta para establecer el deber de cuidado no implica incluir un análisis individual completo, que suponga un juicio individual de reproche al sujeto que infringe la norma de cuidado. La "misma posición del autor" no implica todavía un juicio de reproche individual ${ }^{47}$. La situación, con la consideración del paciente, de las circunstancias del hecho y del autor, define en concreto el deber de cuidado y puede llevar a precisar una lex artis ad-hoc, sin un examen individual sobre la concreta exigibilidad de la norma para ese infractor ${ }^{48}$. El Tribunal

45 Jorge Barreiro (1990) 49 y 50.

46 Este análisis toma una noción de norma penal que integra imperativos y valoraciones, cuya infracción se examina por etapas o niveles según el parámetro que se tome.

47 Mir Puig, Santiago (2008). Derecho penal. Parte general. 8a ed. Barcelona: Reppertor, p. 291, señala que la separación entre el "deber objetivamente exigible" y el "poder individual" no implica descartar la situación del autor, que determina el deber objetivo de cuidado sobre la base de "lo exigible a un hombre diligente en la situación concreta del autor". STRATENWERTH (2005) 506 y 136, entiende que ya en los deberes de cuidado se considera cierta capacidad, pues la prohibición no puede abarcar más que la "capacidad humana de dominar los cursos del acontecer". El "poder" tendría un lugar en lo injusto y otro en la culpabilidad. En el primer caso importa al tratarse de conductas voluntarias y en la culpabilidad se considera como posibilidad de reconocer la exigencia del deber y conformarse a ella, una "posibilidad de decisión responsable". En similar sentido, van Weezel (2008). 187, 190 y 193, pretende mantener la separación entre "tipicidad" y culpabilidad, a pesar de incluir las capacidades especiales en el injusto. Además de distinguir la materia de la prohibición en el tipo de las condiciones en que tal exigencia jurídica puede dirigirse a un sujeto, señala que la posibilidad real de actuar toma la perspectiva individual, con capacidades corporales e intelectuales y conocimientos técnicos, que distingue de la configuración psíquica del sujeto o de los factores de su motivabilidad.

48 Bustos Ramírez, Juan (1995). El delito culposo. Santiago: Editorial Jurídica de Chile, pp. 40-42, precisa que no tiene sentido la discusión entre doctrinas generalizadoras e individualizadoras porque el deber de cuidado siempre se establece con base en la concreta situación, 
Supremo español ${ }^{49}$ describe esta lex artis como: “...aquel criterio valorativo de la corrección del concreto acto médico ejecutado por el profesional de la Medicina -ciencia o arte médico- que tiene en cuenta las específicas características de su autor, de la profesión, la complejidad del acto y la trascendencia vital para el paciente, y en su caso, la influencia de factores endógenos -estado o intervención del enfermo, de sus familiares o de la misma organización sanitaria- para calificar dicho acto conforme o no a la técnica normal empleada." La comprensión del sentido antinormativo de la conducta realizada supone una apreciación mayor que se vincula con su imputación final al agente, la determinación del autor culpable ${ }^{50}$. Algo más se verá al respecto en la estructura subjetiva de la imprudencia, que también se examina a nivel de injusto y de imputación personal o culpabilidad.

\section{(b) Influencia del principio de confianza}

En la actividad médica aparece otra situación relevante al precisar el deber de cuidado: la posibilidad de compartir riesgos cuando se trabaja en equipo, ¿cuál es el cuidado debido de cada interviniente? Para delimitar la norma de cuidado tiene relevancia el llamado "principio de confianza", que justamente se desarrolló en un ámbito de riesgo donde existen diversos actores, el de la conducción en el tráfico viario o rodado. Según este principio, los sujetos pueden actuar confiando en que los demás cumplirán las normas. Su vigencia no es total. Tiene mayor eficacia en un plano horizontal o de igualdad, que en una relación vertical o de superioridad y subordinación. En el ámbito médico se distingue más claramente entre quienes tienen igual jerarquía, por ejemplo, un médico cirujano y un médico anestesista. En este plano cada interviniente puede confiar en que el otro hará o cumplirá lo que le compete. Desde un punto de vista vertical, cuando existe una relación de jerarquía como en el caso de un médico y de un auxiliar, el principio de confianza tiene menos fuerza. El superior

que obliga a considerar las características específicas del sujeto actuante. Esta solución toma la distinción entre la valoración abstracta del tipo legal y su concreción en una referencia sustancial. No termina de resolver los conflictos entre el ámbito del deber y el de la culpabilidad, pero ya anuncia distintos niveles de valoración que sirven para completar el análisis que facilita su separación.

49 Tribunal Supremo español. 7 de febrero de 1990. RJ. 1990\1668. Así también, Tribunal Supremo. 29 de junio de 1990. RJ. 1990\4945; Tribunal Supremo. 11 de marzo de 1991. RJ. 1991\2209, etc.

50 Tiene relevancia la distinción de Mir Puig, Santiago (1994). "Antijuridicidad objetiva y antinormatividad en Derecho penal". Anuario de Derecho Penal y Ciencias Penales. T. XLVII. Fasc. I, pp. 5-28, pp. 27 y 28, entre antijuridicidad y antinormatividad (antijuridicidad completa). Como imputación total o plena, ver Vargas Pinto, Tatiana (2007). Delitos de peligro abstracto y resultado. Determinación de la incertidumbre penalmente relevante. Pamplona: Thomson Aranzadi, pp. 431-433. 
no puede confiar en que quien está a su cargo cumpla efectivamente con la orden impartida o con la función encargada. Este principio delimita del deber de cuidado y no determina su infracción ${ }^{51}$. Por ejemplo, el cirujano puede confiar en que el anestesista realice una conducta propia de su especialidad sin que deba extender su actuar a verificar que lo haga. El comportamiento debido del cirujano se delimita hasta lo que le toca al anestesista, pero esto no significa que aquel no tenga responsabilidad si no cumple con el cuidado exigido en esa cirugía.

Este principio rige solo hasta que existe una duda sobre la adecuación de la conducta del otro. Cuando hay indicios de un comportamiento incorrecto no se puede seguir confiando; el deber de cuidado se amplía o se entiende que surge un "deber de cuidado secundario" 52 . Interesante resulta la sentencia de la Corte de Apelaciones de Concepción de 200853, ratificada por la Corte Suprema ${ }^{54}$, respecto de un procedimiento entre un médico y una enfermera, en el que el principio tiene relevancia incluso frente a esta última. Se registra que el profesional médico manifestó dudas sobre la cantidad de jeringas. Cuestiona no solo la cantidad; expresa que no le "calzan". Este médico no verifica la naturaleza del contenido de las jeringas, tampoco lo hace la enfermera. En el dictamen se establece que "no cabe aquí admitir la excusa de la enfermera Rabanal en orden a que el procedimiento intratecal es un acto médico indelegable y, por tanto, de exclusiva responsabilidad de la médico Magdalena Celis, porque en este caso se está evidentemente en presencia de un trabajo médico de equipo, en que todos participan con su particulares y parciales actos a la realización del fin común, y por tanto, si bien ella no inoculó al paciente el medicamento que causó su muerte, colaboró en la administración del mismo preparando al paciente para ser inyectado y con sus dichos cooperó activamente para mantener el equívoco respecto de la naturaleza de los medicamentos que debían administrarse vía intratecal." También el caso de aborto ${ }^{55}$ con el que se presentó la problemática de la imprudencia médica introdujo consideraciones sobre la confianza. La defensa del médico imputado sostuvo el principio con relación a la enfermera, en cuanto este confió que ella no se retiraría y seguiría sus instrucciones. El voto

51 Puppe, Ingeborg (2006). "División del trabajo y de la responsabilidad en la actuación médica". Traducción de Nuria Pastor. InDret, $\mathrm{N}^{\circ} 4,13$ pp., p. 5, precisa que este principio tiene exclusivamente la función de limitar los deberes de cuidado y no la responsabilidad de quienes intervienen.

52 Ver Silva Sánchez, Jesús-María (1994). “Aspectos de la responsabilidad penal por imprudencia de médico anestesista. La perspectiva del Tribunal Supremo”. Derecho y Salud. Vol. 2, pp. $41-58$, p. 42

53 Corte de Apelaciones de Concepción. 23 de julio de 2008. Rol: 1326-2005.

54 Corte Suprema. 16 de junio de 2009. Rol: 5076-2008.

55 Corte de Apelaciones de Coyhaique de 5 de marzo de 2008, Rol: 32-2007, con relación a la citada CS. Rol: 1882-2008. 
disidente de la Ministro Araneda Espinoza de la Corte de Apelaciones de Coyhaique se pronuncia al respecto. Señala que se opone al principio de confianza la "teoría del trabajo en equipo en que los miembros observan a su líder y según la actitud de este, es su desempeño", sin perjuicio del modo en que se plantea. Esta idea obedece a la menor eficacia de este principio en las relaciones verticales, que puede hacer surgir el citado deber secundario de cuidado y no implica necesariamente responsabilidad penal.

\section{(4.1.2) Infracción del deber de cuidado}

La delimitación de la norma de cuidado no determina per se la creación de un riesgo penalmente relevante. Interesa la infracción al cuidado debido, en cuanto ella crea un peligro que contradice la norma y que, por tanto, excede de lo permitido en ese ámbito. En similar sentido, el consentimiento informado del paciente sirve para fijar riesgos permitidos por la necesidad de la intervención a la que el paciente-víctima consiente. De hecho, Puppe ${ }^{56}$ explica la relevancia del consentimiento informado para decidir cuál es el riesgo mayor y cuál es el menor como especial justificación en un contexto de necesidad. El consentimiento de la víctima por sí solo tiene una vigencia muy restringida, sobre todo cuando se trata de bienes vinculados con la existencia de la persona, como la vida, la salud y la integridad corporal. La situación cambia en el ámbito médico -en operaciones salvadoras en general- precisamente por las exigencias de la intervención, sus características y finalidades. La voluntad de la víctimapaciente como justificación no se considera aisladamente, sino que en una situación de conflicto entre bienes y males, propia de un estado de necesidad $^{57}$. El consentimiento informado fija un ámbito permitido, pero aun así el facultativo puede no desempeñarse con el cuidado al que estaba obligado. Si su conducta excede de los límites tolerados, crea un riesgo penalmente relevante y cabe su imputación al agente. Los criterios de imputación objetiva de la conducta, que tienen especial relevancia en la imprudencia, son comunes a todo delito y se distinguen de los delitos dolosos, como destaca Sancinetti ${ }^{58}$, por su intensidad. Una vez que se

\footnotetext{
Puppe (2007) 4 y ss.

En general, Politoff / Ortiz (Directores); Matus (Coordinador) (2002) 140 y 141.

SancinetTi, Marcelo (1997). Subjetivismo e imputación objetiva en Derecho penal. Buenos Aires: Ad-Hoc, pp. 73, 134. Los delitos dolosos suponen un paso más allá con relación al riesgo creado, pues la peligrosidad ex ante de la conducta no solo se conoce sino que se busca. Fernández Cruz (2002) 106, subraya este fundamento normativo de la imprudencia, pero aclara que también está en el dolo, solo que allí la infracción del deber es "tan palmaria" que no requiere detenerse o insistir. La distinción de magnitud en este aspecto lo muestra especialmente Јаковs, Günther (1972). Studien fahrlässigen Erfolgsdelikt. Berlin: de Gruyter, pp. 104 ss; Јаковs (1995) 312 ss.
} 
imputa la conducta, puede ser que no se produzca un resultado lesivo. Nada habrá que imputar ex post. También es posible que exista un resultado dańoso que se deba a otro factor y no a tal conducta. No basta imputar un comportamiento ni siquiera si hay daño. Además, es necesario vincular el resultado a esa conducta.

\section{2) IMPUTACIÓN DEL RESULTADO}

Como se observó, otro de los requisitos que se señalan para establecer responsabilidad penal es la existencia de una relación causal, aunque simplemente se nombre como un elemento más de imputación. La causalidad es un vínculo que se da entre una acción y un efecto material, como una operación descuidada y la amputación de algún miembro. Este nexo entre intervención y consecuencia no es suficiente. Es una primera conexión entre acción y efecto material a nivel de tipicidad y se exige una vinculación normativa, que analice los riesgos creados frente a la afectación de aquello que se protege jurídicamente. Se habla de la necesidad de imputar objetivamente el resultado a la conducta ${ }^{59}$. En general, este se imputa cuando se muestra como la concreción del riesgo creado por la conducta peligrosa, que se excede de lo permitido ${ }^{60}$. De hecho, si se vuelve a la sentencia de la Corte Suprema sobre aborto imprudente, se deja constancia de que "el riesgo generado por la negligencia omisiva del equipo médico y no otro, el que en definitiva se materializó, directa e inequívocamente, en el resultado de muerte de la criatura que llevaba la madre en su vientre, que es quien tiene la calidad de sujeto pasivo". De modo que si es concreción de otro riesgo no cabe imputarse. Puede ocurrir que un médico cree objetivamente un peligro relevante si, por ejemplo, deja una compresa dentro del cuerpo del paciente y que este desarrolle un paro cardiorrespiratorio por una dosis inadecuada de anestesia porque el anestesista creó otro riesgo relevante al que cabe imputarse el resultado muerte.

La imputación final de lo injusto - desde una concepción que no se satisface con normas de determinación y que contempla valoraciones ${ }^{61}$ no se agota con la creación de un riesgo prohibido ex ante y requiere la producción de un resultado ex post por aquel riesgo. Por eso se ha señalado que en la imputación del resultado se trata de identificar el riesgo que

59 La insuficiencia de la causalidad y la necesidad de otro vínculo se destaca penalmente a partir de Honig. Ver Honig, Richard (2009). "Causalidad e imputación objetiva” en Sancinetti, Marcelo (comp.): Causalidad, riesgo e imputación. Buenos Aires: Hammurabi, pp. 105-134, pp. 105-134.

60 Se reconoce como el segundo pilar fundamental de imputación básicamente gracias a los estudios de Roxin (1997) 362 ss.

61 Los requisitos de imputación cambian, como se ha dicho, según la noción de injusto que se tome y pudiera bastar la creación de un riesgo ex ante prohibido si lo injusto se conforma con una norma de determinación. 
aparezca como su explicación ${ }^{62}$. De modo que no solo es necesario que se cree un riesgo, ni siquiera que se produzca también un resultado lesivo para la situación protegida por la norma. Ambos han de estar conectados fáctica y jurídicamente. Junto a la causalidad, debe haber una relación de riesgo entre la conducta peligrosa y el resultado ${ }^{63}$. Jorge BARreiro ${ }^{64}$ habla de una relación normativa, un "nexo de antijuridicidad", donde el resultado ha de ser consecuencia de la infracción del deber objetivo de cuidado, en cuanto ese resultado fuera de aquellos que la norma de cuidado infringida trataba de evitar. El problema es que luego señala que la imputación objetiva del resultado requiere también una "relación de adecuación", como la previsibilidad objetiva del resultado por la conducta descuidada. Se refiere al deber subjetivo de cuidado aunque se realiza con parámetros objetivos, que no tienen en cuenta consideraciones personales del agente. Sucede que la estructura de la imprudencia tiene aspectos subjetivos que aparecen difusa y confusamente en la determinación de la norma de cuidado, quizá por su menor intensidad frente al dolo, y que se presentan en las consideraciones finales. Por otro lado, para establecer la relación de riesgo ańade otros criterios superfluos o no conectados con el resultado. Junto con el fin de protección de la norma, agrega el de la conducta alternativa ajustada a Derecho y la teoría del aumento del riesgo. En el primer caso se incorpora un juicio hipotético que impide imputar el resultado si este se hubiere producido igualmente con una conducta conforme a la norma. Sin embargo, se trata de verificar si el resultado se debe a la conducta infractora o a un factor ajeno, no contemplado por el fin de la norma. Por su parte, el aumento del riesgo por sobre los niveles permitidos se refiere a la conducta prohibida y no al resultado.

\section{5) CONSIDERACIONES FINALES EN TORNO A LA IMPUTACIÓN DEL RE- SULTADO Y LA ESTRUCTURA DE LA IMPRUDENCIA}

También la imputación del resultado plantea dificultades que explican la inclusión de aspectos más allá de la mera constatación de su relación con la conducta que crea un riesgo jurídicamente relevante. Ocurre que, si bien el examen del nexo entre el riesgo prohibido ex ante y la con-

\footnotetext{
62 Cancio Meliá, Manuel (2004). "Aproximación a la teoría de la imputación objetiva”. En Díaz-Aranda, Enrique / Cancio Meliá, Manuel: La imputación normativa del resultado a la conducta. Buenos Aires: Rubinzal-Culzoni Editores, pp. 15-43, p. 34, con relación a la explicación de Jаковs.

63 En este sentido, Mir Puig, Santiago (2001). "Significado y alcance de la imputación objetiva en Derecho penal” en Cerezo Mir, José: Modernas tendencias en la ciencia del Derecho penal y en la criminología. Madrid: Universidad Nacional de Educación a Distancia, pp. 389-408, pp. 394 ss.

64 Jorge Barreiro (1990) 64-69.
} 
secuencia lesiva ex post importa una apreciación objetiva, esta atribución se refiere a una conducta personal que conlleva aspectos subjetivos, evidentes sobre todo cuando se habla de una conducta imprudente. Entonces, ¿también hay consideraciones subjetivas en la imputación "objetiva" del resultado? Aunque el problema aparece ya en la delimitación del deber de cuidado con la referencia a conocimientos y aun a ciertas capacidades especiales del profesional médico, el desarrollo de la llamada teoría de la imputación objetiva a partir de Honig ${ }^{65}$ para la imputación del resultado no aparece tan objetiva. Parte de una conducta como manifestación de voluntad y considera imputable el resultado que es "propuesto como fin". En cualquier caso, habla de una "finalidad objetiva", una "posibilidad objetiva de la conducta de perseguir fines", que remite a un observador objetivo y a tesis generalizadoras, a pesar de la relevancia que atribuye a la consideración del caso concreto.

\section{1) AsPeCtos SUbJETIVOS}

Sin entrar en el juicio de reproche individual que se centra en la culpabilidad -como último nivel de imputación- ni en la discusión sobre los límites entre injusto y culpabilidad, estas reflexiones no pueden dejar de cuestionar lo subjetivo la imprudencia como tradicional "elemento subjetivo". No parece quedar mucho si se determina como un concepto normativo y la imputación de la conducta se hace desde un deber objetivo de cuidado, una conducción material que no observa la lex artis y los demás parámetros que determinan el deber de cuidado. La mera infracción de un deber objetivo de cuidado por un comportamiento externo, aunque se concrete en el resultado, no parece satisfacer exigencias de imputación de la imprudencia. El resultado debe estar conectado a la conducta también por un nexo subjetivo: por la previsibilidad del riesgo, se haya o no previsto. Normalmente, el agente que realiza una conducta médica prevé que puede producirse un resultado dañoso y confía en que no ocurrirá, no busca su efectiva producción como fin (directamente) ni como medio (indirectamente) ${ }^{66}$. Se observa una vinculación subjetiva entre conducta y resultado propia de la llamada imprudencia con representación o culpa consciente. Incluso se confunde con el llamado dolo eventual, donde también hay representación de un probable resultado, una conciencia de

\footnotetext{
65 Honig (2009) 114 y ss.

66 Una interesante Corte Suprema. 20 de noviembre de 1997. Rol: 376-1997, se remite a la tesis o regla del "voluntario indirecto" para la imputación de efectos dañinos no buscados. Para que la conducta sea lícita y no proceda la atribución de esos efectos, ella debe ser buena o indiferente; el agente debe tener un fin honesto, que intente el efecto bueno; el efecto inmediato debe ser el bueno y debe existir una causa proporcionada que "compense" el mal producido.
} 
riesgo ${ }^{67}$. También puede no conocerse la probabilidad de tal efecto, pero habrá imprudencia si el resultado era previsible en términos de que el agente haya debido representárselo.

El comportamiento del facultativo médico puede crear un riesgo prohibido, porque excede los límites permitidos o porque derechamente tiene lugar fuera del ámbito tolerado, que se realiza en un resultado dańoso cuya producción ni siquiera haya sido previsible por tal conducta. En este caso, aunque se imputa una conducta peligrosa y se causa una consecuencia lesiva que se conecta objetivamente con ella, falta no solo la representación del resultado como posible efecto de tal comportamiento, sino que ni siquiera cabía semejante previsión. Hacer responsable al agente supondría cargarlo con las consecuencias de su conducta por ser peligrosa sin considerar nexos subjetivos, que se asemeja a los llamados "delitos cualificados por el resultado", donde se obliga a soportar otras gravosas "ramificaciones" imprevisibles por estar conectadas objetivamente con la conducta del agente.

Las declaraciones que afirmen alguna clase de responsabilidad objetiva en materia penal han de rechazarse. Es difícil que ocurran supuestos como los descritos porque normalmente los resultados son previsibles aunque en el hecho no se prevean, sobre todo en el ámbito médico. Así, la previsibilidad del resultado por la conducta que se realiza muestra el lado subjetivo de la imprudencia ${ }^{68}$. Pero, ¿es una previsibilidad sin más ${ }^{69}$ ? Nadie contestaría de modo afirmativo seriamente, pues todo puede ser previsible, menos lo imposible claro está. Se trata de determinar si en el caso concreto existía un deber de prever el resultado por la conducta realizada, que se infiere de la clase de comportamiento, su peligrosidad, y se determina también con relación a la concreta posición del autor. Nino ${ }^{70}$

67 Distintas tesis, diferencia de magnitud de la representación respecto de la probabilidad del resultado. En general, en nuestro medio se entiende que en el dolo eventual existe además una voluntad que se manifiesta como indiferencia o conformidad respecto del posible resultado. Así, Corte Suprema. 18 de noviembre de 2008. Rol: 6222-2007.

68 Algunos, como Corcoy Bidasolo (2005) 123, 124, consideran que el "deber" subjetivo determina el deber objetivo de cuidado, por lo que no sería independiente. En este sentido, afirma que en la determinación del cuidado objetivo se realiza un juicio de previsibilidad objetiva sobre los conocimientos especiales del individuo (p. 261).

69 En general, nuestros tribunales agregan la previsibilidad del resultado solo para distinguir la imprudencia del dolo, donde el resultado se busca. Por ejemplo, Corte de Apelaciones de Santiago. Rol: 302-2005; Corte de Apelaciones de Concepción. Rol: 951-2007; CS. Rol: 9-2003.

70 Nino (2006) 427-432, entiende que en los casos de conocimiento intermedio existe una "consiente" ejecución de una actividad genéricamente peligrosa, por lo que la atribución subjetiva estaría dada por el conocimiento de la peligrosidad genérica de la conducta. Situación que lo lleva a afirmar la necesaria distinción de gravedad entre la imprudencia (consciente), que conoce la peligrosidad concreta de la conducta, negligencias intermedias, que advierte la peligrosidad genérica, y la "negligencia" (imprudencia inconsciente). Como esta diferencia no se plasma jurídicamente tampoco en nuestro Derecho, interesa reflejarla al momento de graduar la pena dentro de los marcos legales. 
distingue un ámbito intermedio entre los casos de "negligencias" en que falta el conocimiento de la peligrosidad genérica y que, por tanto, no satisfacen el "principio de asunción de pena" y los de imprudencia donde se advertiría el resultado como posible, la peligrosidad concreta de la conducta. Son supuestos en los que no se conoce la peligrosidad concreta de la conducta, pero sí su peligrosidad genérica. Uno de los ejemplos que cita es el de un médico que conoce que cierta droga es peligrosa para personas con problemas cardíacos y que, confiando en la improbabilidad de que los pacientes tengan tales males, omite hacer los exámenes para averiguar alguna afección de ese tipo, por lo que en el hecho no conoce el riesgo del medicamento para los pacientes a los que se lo prescribe.

La obligación de prever el riesgo de un dańo se destaca en forma particular en un pronunciamiento de la Corte Suprema de 1997 ya citado $^{71}$, frente a la producción de daños no buscados directamente pero que se producen en forma necesaria y que son, por tanto, previsibles. Manifiesta que, aun en estos casos, para imputar un efecto malo se requieren "tres condiciones: previsión, posibilidad de impedirlo y obligación de hacerlo". Esta idea remite de nuevo a una noción normativa, con la anotación de que el deber de previsión es un deber subjetivo o interno de cuidado. De modo que si un facultativo médico no prevé las consecuencias lesivas de su conducta peligrosa, aquellas pueden atribuirse también subjetivamente a tal conducta si tenía el deber de prever su producción y no lo hizo. La vinculación subjetiva se observa aquí no por el conocimiento del riesgo concreto, sino por la falta de un conocimiento debido al infringir un deber subjetivo de cuidado. Esta sola imputación no supone la creación de un riesgo objetivo, es decir, una imputación objetiva. El médico puede no conocer el riesgo de la conducta debiendo haberlo hecho y, a pesar de ello, comportarse con precaución sin crear riesgos relevantes penalmente. La infracción de este deber subjetivo implica el desconocimiento de la peligrosidad (concreta) de la conducta, pero tampoco niega todo conocimiento. Como todo es posible, el deber se establece con relación a los conocimientos del autor en esa situación. No habrá un deber subjetivo de cuidado si el agente no tenía la posibilidad de conocer los riesgos de su actuación. Esta posibilidad se examina en concreto y solo se transformará en un deber si la conducta que se asume o realiza es de tal magnitud que en ese caso debió omitirse o desarrollarse con medidas de cuidado. Ello ocurrirá no cuando falte todo conocimiento del riesgo, sino cuando el autor conozca al menos la peligrosidad genérica de su conducta, como diría Nino: en casos de "negligencias intermedias". Las meras negligencias no harán surgir deber alguno porque falta toda vinculación subjetiva. En la imprudencia siempre existe un conocimiento que del hecho por su autor,

71 Supra, nota 66. 
solo que no coincide con el dolo, es de menor intensidad respecto de la probabilidad de realización del hecho típico.

\section{2) ESTRUCTURA DE LA IMPRUDENCIA Y EXIGENCIAS DE IMPUTACIÓN}

Es tal la calidad subjetiva de la imprudencia como forma de comportamiento humano, que no puede esconderse siquiera en el juicio normativo que implica ${ }^{72}$. Se observó que incluso se discute la consideración de aspectos subjetivos al determinar la norma objetiva de cuidado cuando se introducen conocimientos especiales. En realidad, toda infracción de "deber" lleva a cuestionar la real separación entre antijuridicidad y culpabilidad en cuanto no existe un verdadero deber si no se puede cumplir. Ciertamente, el concreto deber surgirá de la clase de conducta y del sujeto que la realizó. Ha de considerar el destinatario de la norma y esto supone tener en cuenta el conocimiento de la conducta realizada, pero no necesariamente (todavía) la comprensión de su sentido antijurídico. Un conocimiento y comprensión total genera la confusión de categorías (injusto y culpabilidad) ${ }^{73}$. El mismo Roxin ${ }^{74}$, que considera los conocimientos especiales para determinar el deber de cuidado, destaca que tal unificación es producto de las tesis individualizadoras extremas de lo injusto, al volver a la forma más antigua de la teoría de los imperativos. Kindhäuser ${ }^{75}$ ratifica esta idea de construcción del delito propia de una teoría imperativista radical que considera todos los criterios de imputación al autor individual. Critica esta teoría, pero también la imputación objetiva de Honig, que,

72 Schünemann (2009) 353, subraya la superposición de categorías normativas desde la misma conducta voluntaria, que no pudo evitar ni siquiera von Liszt y BELING, pues siempre supone un poder individual. Además, este solapamiento se evidencia a partir de la teoría finalista del injusto personal, como también de la ampliación de la noción de culpabilidad con consideraciones preventivas, su ampliación como categoría del delito derivada de la responsabilidad y de la funcionalización por igual del injusto y de la culpabilidad con la "dañosidad social" desde los fines de la pena (pp. 330 y 331). Stratenwerth (2005) 136, considera cierta capacidad en lo injusto por tratarse de una conducta voluntaria, aunque no se busque el resultado producido. Hay conocimiento y voluntad. Por eso reconoce el "poder" en lo injusto, aunque limitado a la conducta como "capacidad humana de dominar los cursos del acontecer". En la culpabilidad sería "posibilidad de decisión responsable".

73 Schünemann (2009) 327, 328, 343, describe la separación de estas categorías como uno de los avances más importantes de los últimos tiempos, que no cabe abandonar. Afirma que desde los fines del Derecho penal tiene que derivarse dos perspectivas de valoración que determinan la diferencia: la lesividad social, que considera la víctima y la valoración social del hecho, y la evitabilidad individual, que se vincula con el autor. Como admite que esas valoraciones se superponen, se preocupa de resolver el problema según la "mayor afinidad" que exista con la lesión social o con la reprochabilidad y si la perspectiva externa no lo soluciona de modo unívoco señala que ha de acudir a la perspectiva jurídico-dogmática interna. Aclara que la armonización entre la perspectiva externa e interna solo es posible si el legislador considera injusto y culpabilidad según esos criterios (pp. 353-356).

$74 \quad$ Roxin (1997) 1016.

75 KindHÄUSER (2008) 9. 
como se dijo, incorpora consideraciones subjetivas "objetivadas" 76 . Afirma que interesan los conocimientos y capacidades del destinatario de la norma como capacidad de acción, que distingue de la capacidad de motivación conforme a la norma. Esta última se da en un nivel más concreto de juicio. De hecho, para tal separación se vale de un "silogismo práctico"77 y de la distinción de niveles de juicio, donde la culpabilidad sería el último filtro de imputación ${ }^{78}$.

Todo injusto ha de imputarse objetiva y subjetivamente, aun en el ámbito de la imprudencia médica. Su atribución pasa primero por verificar una conducta, un resultado y una relación causal según el supuesto descrito en el tipo penal al que se asignan y luego por la imputación objetiva y subjetiva de la conducta y del resultado según la norma primaria que se deduce del tipo, que importa la creación de un riesgo prohibido ex ante, la perturbación a un bien protegido y una relación de riesgo que los conecte objetiva (imputación objetiva del resultado) y subjetivamente (conciencia potencial de riesgo por deber de prever el resultado ${ }^{79}$. Así, la estructura objetiva y subjetiva de la imprudencia exige para imputar un

76 KindhäUSER (2008) pp. 10-17, 21 y ss.

77 En la premisa mayor está el objetivo que se quiere alcanzar (la evitación obligada del tipo), en la premisa menor está el conocimiento que el sujeto tiene de este objetivo, que en la imprudencia se estructura como representación parcial del objetivo, un riesgo parcial conocido. En la conclusión se indica el comportamiento cuidadoso.

78 KindhäUser (2008) 6-8, 16, describe la culpabilidad como un "concepto relacional ulterior" necesario para la plena responsabilidad. Más que su conexión con reglas específicas de imputación, se subraya la distinción de niveles de juicio tanto respecto de la culpabilidad, que tiene por objeto el injusto, como de la separación entre antijuridicidad y tipicidad. Expresa que la primera no es una propiedad de la segunda, sino un predicado que la presupone. Así también se entiende la distinción entre el objeto de imputación por una norma y la comprobación final de si podía evitarse. Interesa particularmente la utilidad de la noción de "filtro", al verificar que dos filtros solo son funcionales si el filtro posterior es más estrecho que el anterior. La disfunción se produce cuando el filtro anterior no deja pasar algo que el posterior sí debería dejar pasar, como en el caso de los conocimientos especiales. En términos similares, MAÑALICH (2010) 175 y ss., distingue dos niveles de imputación: uno relativo al injusto personal, según la "capacidad de acción intencional", y otro vinculado con la culpabilidad, que se determina por la "capacidad de motivación", de "reflexividad de la intencionalidad". Más que la separación entre norma e imputación, que es compleja, interesa destacar los niveles de valoración, que también admite frente a la tipicidad. Señala que la antinormatividad es una "propiedad secundaria" de todo comportamiento que exhibe las propiedades primarias exigidas por la descripción típica (p. 172).

79 Se destaca la distinción de Fernández Cruz (2002) 107-110, entre la infracción del deber de cuidado y los criterios normativos de imputación objetiva del resultado, aunque considera aquella infracción dentro de la acción típica y no habla de imputación objetiva de la conducta por la creación de un riesgo jurídicamente relevante frente al objeto de la norma. Asimismo, exige una relación causal además de la concreción del riesgo en el resultado (relación de riesgo), pero contempla ambas vinculaciones en la teoría de la imputación objetiva como "doble valoración". Finalmente, incluye la previsibilidad como criterio de imputación subjetiva, sin embargo, afirma que ha de ubicarse en la imputación personal a la vez que la integra al tipo subjetivo. No se comprende su ubicación ni la relación con otros aspectos subjetivos del juicio de reproche personal. 
injusto: conducta creadora de un riesgo jurídicamente relevante; resultado antijurídico; causalidad entre acción y efecto si procede (delitos de resultado material por acción) y relación de riesgo entre la conducta riesgosa y el resultado jurídico; y previsibilidad de tal resultado por esa conducta se haya o no previsto, es decir: conciencia de riesgo o infracción de una norma subjetiva de cuidado (debía representárselo: casos de error de tipo evitable) ${ }^{80}$. Claro que solo habrá delito y procederá la imputación total o final cuando se determine que el cumplimiento de la norma le era exigible concretamente al autor, que pasa a ser "autor culpable".

\section{BIBLIOGRAFÍA}

- Alexander, Clarence (1949). The Law of arrest in criminal and others proceedings. Buffalo, N. Y: Dennis \& Co. Vol. 2.

- Binding, Karl (1922). Die Normen und ibre Übertretung. Frankfurt del M.: Liepzig. Vol. I (reimp., Aalen, Hamburg, 1991).

- Bustos Ramírez, Juan (1989) Manual de Derecho penal: Parte general. $3^{a}$ ed. Barcelona: Ariel.

- (1995). El delito culposo. Santiago: Editorial Jurídica de Chile.

- (2007). Obras completa. 2a ed. Santiago: EJS. T. II.

- Cancio Meliá, Manuel (2004). "Aproximación a la teoría de la imputación objetiva”. En Díaz-Aranda, Enrique; Cancio Meliá, Manuel. La imputación normativa del resultado a la conducta. Buenos Aires: Rubinzal-Culzoni Editores, pp. 15-43.

- Cerezo Mir, José (2008). Derecho penal: Parte general. Montevideo Buenos Aires: B de F.

- Corcoy Bidasolo, Mirentxu (2005). El delito imprudente. 2a ed. Montevideo-Buenos Aires: B de F.

- Cury Urzúa, Enrique (1981). "Contribución al estudio de la responsabilidad médica por hechos culposos". Revista de Ciencias Penales. T. XXXVII (1978-1981), pp. 97-105.

- Cury Urzúa, Enrique (2005). Derecho penal: parte general. $7^{a}$ ed. Santiago: Ediciones Universidad Católica de Chile.

- Cramer. $\$ 15$. En Schönke, A. / Schröder, H. (2006). Strafgesetzbuch Kommentar. München: Aufl. Beck.

80 En similar sentido, salvo por la consideración de la previsibilidad, Romeo Casabona, Carlos María (2005). Conducta peligrosa e imprudencia en la sociedad del riesgo. Granada: Comares, pp. 2 y 205, describe los elementos del tipo de lo injusto en los delitos de acción imprudente: infracción del deber de cuidado; resultado material o "peligro concreto" en los delitos imprudentes de resultado, relación de causalidad en éste e imputación objetiva del resultado. 
- Etcheberry, Alfredo (2001). Derecho penal: parte general. $3^{\mathrm{a}}$ ed. Santiago: Editorial Jurídica de Chile. T. I.

- (1986). "Tipos penales aplicables a la actividad médica". Revista Chilena de Derecho. T. XIII, pp. 271-280.

- Fernández Cruz, José Ángel (2002). "El delito imprudente: la determinación de la diligencia debida en el seno de las organizaciones". Revista de Derecho de la Facultad de Ciencias Jurídicas y Sociales de la $U A C H$. T. XIII, pp. 101-121.

- Fernández Hierro, José Manuel (1998). Sistema de responsabilidad médica. 2a ed. Granada: Comares.

- Frisch, Wolfgang (2009). "Lo fascinante, lo acertado y lo problemático de la teoría de la imputación objetiva del resultado" en Sancinetti, Marcelo (comp.): Causalidad, riesgo e imputación. Buenos Aires: Hammurabi, pp. 345-381.

- García-Pablos de Molina, Antonio (2006). Introducción al Derecho penal. $4^{\mathrm{a}}$ ed. Madrid: Ramón Areces.

- Garrido Montt, Mario (1986). "Responsabilidad del médico y la jurisdicción”. Revista Chilena de Derecho. T. XIII, pp. 281-288.

- Goldschmidt, James (1913). "Der Notstand, ein Schuldproblem". Österreichische Zetschrift für Strafrecht. N 4, pp. 129-196.

- Gómez Rivero, Ma del Carmen (2008). La responsabilidad penal del médico. 2a ed. Valencia: Tirant lo Blanch.

- Hava García, Esther (2001). La imprudencia médica. Valencia: Tirant lo Blanch.

- Honig, Richard (2009). "Causalidad e imputación objetiva" en Sancinetti, Marcelo (comp.): Causalidad, riesgo e imputación. Buenos Aires: Hammurabi, pp. 105-134.

- Hruschka, Joachim (1994). "Reglas de comportamiento y reglas de imputación". Traducción de F. Baldó Lavilla. Anuario de Derecho Penal y Ciencias Penales. Vol. XLVII. Fasc. III, pp. 343-356.

- Jakoвs, Günther (1972) Studien fahrlässigen Erfolgsdelikt. Berlin: de Gruyter.

- (1995). Derecho penal parte general, fundamentos y teoría de la imputación. Traducción de J. Cuello; J. Serrano. 2a ed. (alemana). Madrid: Marcial Pons. nos Aires: Ad-Hoc.

(1996). La imputación objetiva en el Derecho penal. Bue(2001). ¿Qué protege el Derecho penal: bienes jurídicos o la vigencia de la norma? Traducción de Manuel Cancio Meliá. Mendoza: Ediciones Jurídicas Cuyo.

- Jescheck, H-H; Weigend, T. (2002) Tratado de Derecho penal. Parte general. Traducción de Miguel Olmedo Cardenete. 5a ed. Granada: Comares. 
- Jorge Barreiro, Agustín (1990) La imprudencia punible en la actividad médico-quirúrgica. Madrid: Tecnos.

- KindhäUser, Urs (2008) "El tipo subjetivo en la construcción del delito". InDret, $\mathrm{N}^{\circ}$ 4, 35 pp.

- Künsemüller, Carlos (1986) "Responsabilidad penal del acto médico". Revista Chilena de Derecho. T. XIII, pp. 259-269.

- Luzón Peña, Diego-Manuel (2002) Curso de Derecho penal: parte general I. Madrid: Universitas.

- Mañalich, Juan Pablo (2010). "Norma e imputación como categorías del hecho punible". Revista Estudios de la Justicia. $\mathrm{N}^{\circ} 12$, pp. 165-185.

- Merkel, Adolf (1889). Lehrbuch des deutschen Strafrecht. Stuttgart.

- Mir Puig, Santiago (1994) "Antijuridicidad objetiva y antinormatividad en Derecho penal". Anuario de Derecho Penal y Ciencias Penales. T. XLVII. Fasc. I, pp. 5-28.

- (2001). "Significado y alcance de la imputación objetiva en Derecho penal” en Cerezo Mir, José: Modernas tendencias en la ciencia del Derecho penal y en la criminología. Madrid: Universidad Nacional de Educación a Distancia, pp. 389-408.

- (2008). Derecho penal. Parte general. 8a ed. Barcelona: Reppertor.

- Molina Fernández, Fernando (2001). Antijuridicidad penal y sistema del delito. Prologo de Gonzalo Rodríguez Mourullo. Barcelona: J.M. Bosch.

- Nino, Carlos Santiago (2006). Los límites de la responsabilidad pena. Buenos Aires: Astrea.

- Politoff Lifschitz, Sergio / Ortiz Quiroga, Luis (directores); Matus Acuña, Jean Pierre (coordinador) (2002). Texto y comentario del Código Penal chileno. Santiago: Editorial Jurídica de Chile. T. I, pp. 93-100, 127-144.

- Politoff L, Sergio / Matus A., Jean Pierre / Ramírez G., María Cecilia (2003). Lecciones de Derecho penal chileno: Parte general. Santiago: Editorial Jurídica de Chile.

- Puppe, Ingeborg (2006). "División del trabajo y de la responsabilidad en la actuación médica". Traducción de Nuria Pastor. InDret, $\mathrm{N}^{\circ} 4,13 \mathrm{p}$.

- _ (2007). "La justificación de la intervención médica curativa". Traducción de Felip i Saborit, David. InDret, $\mathrm{N}^{\circ} 1,14 \mathrm{p}$.

- Rodríguez Peña, Pilar (2010). "El consentimiento al acto médico. Una mirada comparada entre el Derecho francés y chileno". Revista de Derecho y Ciencias Penales de la Universidad San Sebastián, No 14, pp. 33-44.

- Romeo Casabona, Carlos María (2005). Conducta peligrosa e imprudencia en la sociedad del riesgo. Granada: Comares. 
- Roxin, Claus (1997). Derecho penal: Parte general. Traducción de la 2a ed. alemana de D. Luzón Peña; M. Díaz y García Conlledo; J. de Vicente Remesal. Madrid: Civitas.

- Sancinetti, Marcelo (1997). Subjetivismo e imputación objetiva en Derecho penal. Buenos Aires: Ad-Hoc.

- Schaffstein, Friedrich (2009). "Disvalor de acción, disvalor de resultado y justificación en los delitos imprudentes". Traducción de Marcelo A. Sancinetti. Causalidad, riesgo e imputación. Buenos Aires: Hammurabi, pp. 217-243.

- Schünemann, Bernd (2009). Obras. Santa Fe: Rubinzal-Culzoni Editores. T. I.

- Silva Sánchez, Jesús-María (1986) El delito de omisión. Concepto y sistema. Barcelona: Bosch.

- (1994). "Aspectos de la responsabilidad penal por imprudencia de médico anestesista. La perspectiva del Tribunal Supremo". Derecho y Salud. Vol. 2, pp. 41-58.

- (2001). "Libertad de terapia e imprudencia médica". Revista Peruana de Doctrina y Jurisprudencia Penales. $\mathrm{N}^{\circ}$ 2, pp. 549-588.

- Stratenwerth, Günter (2005). Derecho penal. Parte general I. Traducción de Manuel Cancio Meliá; Marcelo Sancinetti. $4^{a}$ ed. Buenos Aires: Hammurabi.

- Struensee, Eberhard (1991). "Atribución objetiva e imprudencia". Cuadernos de Politica Criminal. N 44, pp. 449-458.

- Van Weezel, Alex (1999). "Parámetros para el enjuiciamiento de la infracción al deber de cuidado en los delitos imprudentes". Revista Chilena de Derecho. N ${ }^{\circ}$. Vol. 26, pp. 323-336.

- (2008). Pena y sentido. Estudios de Derecho penal. Lima: Ara.

- Vargas Pinto, Tatiana (2007). Delitos de peligro abstracto y resultado. Determinación de la incertidumbre penalmente relevante. Pamplona: Thomson Aranzadi.

\section{JURISPRUDENCIA CITADA}

- Corte Suprema. 22 de julio de 2009. Rol: 5575-2008.

- Corte Suprema. 16 de junio de 2009. Rol: 5076-2008.

- Corte Suprema. 16 de abril de 2009. Rol: 1882-2008.

- Corte Suprema. 18 de noviembre de 2008, Rol: 6222-2007.

- Corte Suprema. 4 de junio de 2008. Rol: 434-2008

- Corte Suprema. 23 de abril de 2007. Rol: 6585-2006.

- Corte Suprema. 19 de enero de 2005. Rol: 9-2003.

- Corte Suprema. 20 de noviembre de 1997. Rol: 376-1997. 
- Corte de Apelaciones de Coyhaique de 5 de marzo de 2008, Rol: 32-2007.

- Corte de Apelaciones de Santiago. 13 de mayo de 2008. Rol: 6974-2005.

- Corte de Apelaciones de Concepción. 5 de agosto de 2008. Rol: 951-2007

- Corte de Apelaciones de Concepción. 23 de julio de 2008. Rol: 1326-2005.

- Corte de Apelaciones de Iquique. 27 de noviembre de 2007. Rol: 267-2007.

- Corte de Apelaciones de Santiago. 25 de septiembre de 2007, Rol: 302-2005.

- Corte de Apelaciones de Santiago. 26 de enero de 2007; Rol: 2556-2006.

- Corte de Apelaciones de Temuco. 5 de diciembre de 2006. Rol: 1258-2006.

- Corte de Apelaciones de Rancagua. 9 de marzo de 2005. Rol: 37-2005-

- Tribunal Oral Penal de Santiago (20). 28 de noviembre de 2006. Ruc: 0500508827-7.

- Tribunal Supremo español. 7 de febrero de 1990. RJ. 1990\1668.

- Tribunal Supremo español. 29 de junio de 1990. RJ. 1990\4945;

- Tribunal Supremo español. 11 de marzo de 1991. RJ. 1991\2209 